\title{
El federalismo en Yucatán: política y militarización (1840-1846)
}

\author{
Maria Cecilia Zuleta Miranda \\ CENTRO DE ESTUDIOS HISTORICOS \\ El Colegio de MÉXICo
}

\begin{abstract}
Este artículo tiene como propósito estudiar los profundos conflictos internos y con el gobierno central ocurridos en Yucatán entre $1839-40$ y 1846 . Se parte de la idea de que estos movimientos políticos se articularon a partir de la definición y defensa de la soberanía territorial, condensada en el principio de la autonomía político-administrativa.
\end{abstract}

$\mathrm{D}$ esde la ruptura con la metrópoli española, Yucatán inició una conflictiva relación con el resto de lo que había sido el territorio de Nueva España. Más relacionado con la región veracruzana $-\mathrm{y}$ aun con el imperio español a través de Cuba, y con el sur de Estados Unidos- que con la ciudad de México, Yucatán pasaría desde 1824 y hasta el estallido de la guerra de Castas en 1847 , por profundas transformaciones en su economía. En este contexto, los yucatecos intentaron obtener una serie de condiciones comerciales y administrativas que le garantizaran una situación de excepción frente al resto de los estados de la república, para lo cual tuvieron que enfrentarse frecuentemente con el gobierno central de la república. Aunque esta lucha fue unas veces sorda y pacífica, política más que militar, otras fue militar y naval, decidiendo Yucatán convertirse en un estado nacional independiente: el "estado libre y soberano de Yucatán".

La historiografía se ha concentrado tradicionalmente, al estudiar el proceso histórico de organización del federalismo mexicano, en resaltar el enfrentamiento entre proyectos liberales y conservadores, más que en 


\section{SECUENCIG}

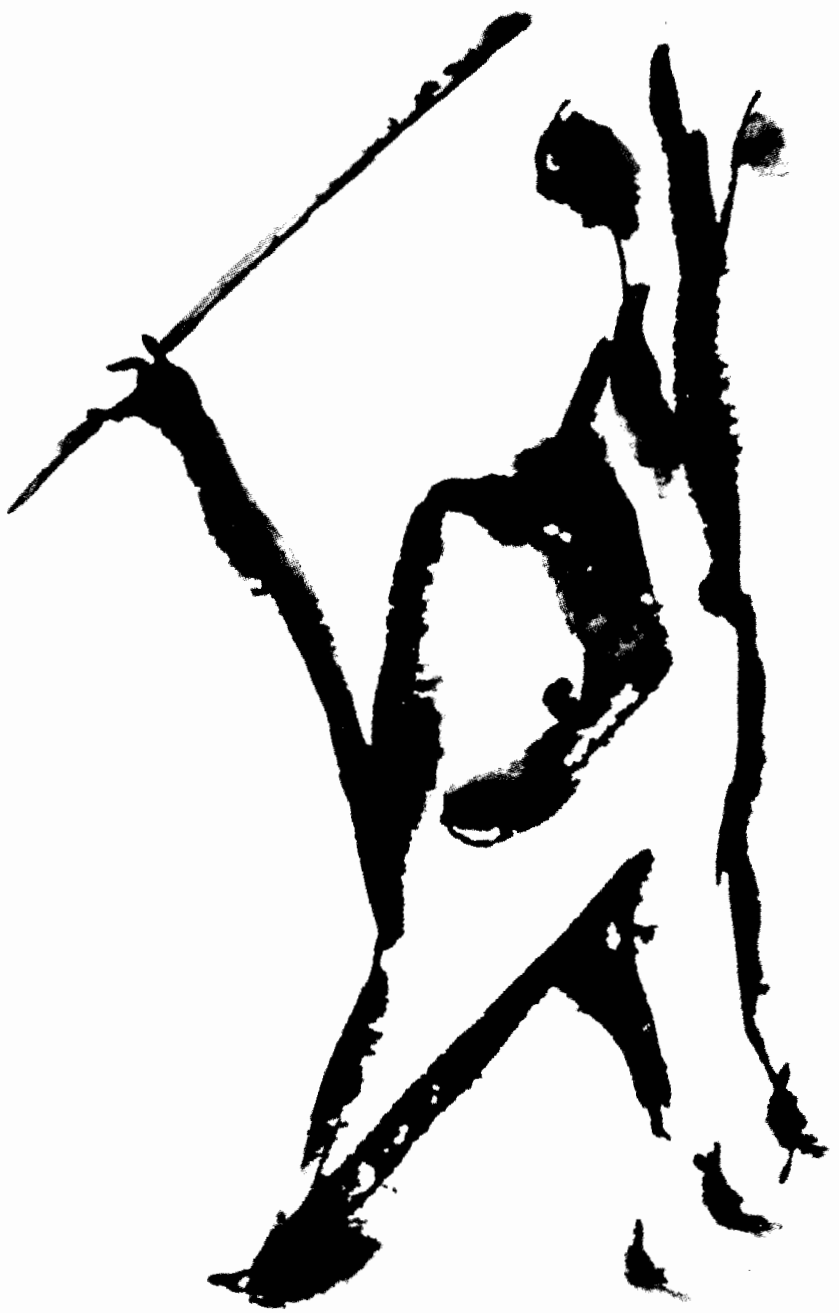

Ilustraciones de Ana Bonilla. Queda estrictamente prohibida la reproducción total o parcial de las imágenes publicadas en este número de la revista Secuencia, 31.

Las imágenes fueron contratadas y/o donadas de forma exclusiva para esta publicación. 
analizar la tensión entre centralización y descentralización política y administrativa en los proyectos constitucionales habidos entre 1824 y 1847. En este contexto, se ha analizado el secesionismo yucateco simplemente como la emergencia de un designio independentista en Yucatán, sin relacionarlo claramente con el proceso de construcción de una organización federal. La historiografia oficial regional, por otra parte, ha simplificado la compleja relación entre México y Yucatán, reduciendo la agitada historia yucateca de ese período simplemente a una búsqueda de la integración a México, o negando las instancias de secesión. Indudablemente, la necesidad política de identificar la historia de Yucatán a la de México ha obscurecido la historia yucateca de la primera mitad del siglo XIX. ${ }^{1}$

En la Constitución de 1824 , los estados lograron institucionalizar su territorialidad frente al Estado central, pero la tensión entre ambos se resol-

1 "Quicnes han hablado de separatismo yucateco lo han hecho por mala fe o ignorancia; históricamente, sociológicamente, lo correcto es calificar el fenómeno de las relaciones entre Yucatán y el resto de México no de separatismo sino, en todo caso, de lo contrario: del integracionismo yucateco a la gran patria mexicana"..."Queda pues refutado con la irrefutable lógica de los hechos que, en el ánimo de los yucatecos de aquellos primeros años de nuestra vida independiente respecto de España, cuando otras provincias mexicanas no resistieron la prueba, dominó siempre el juicio integracionista a pesar de todos los obstáculos geográfìcos, económicos, históricos y culturales." Betancourt Pérez, "Scparatista Yucatán?", en Pérez Betancourt y Ruz Menéndez, Yucatán, vol. I, pp. 316 y 329. vería aparentemente a favor de este último con la aprobación de las Siete Leyes en 1836.2 En este contexto, entre 1839 y 1840 , Yucatán se levantó contra la organización departamental y arancelaria impuesta por las Siete Leyes, iniciándose entonces lo que sería una constante en los siguientes treinta años: el conflicto político y social en el sureste yucateco.

Los enfrentamientos entre Yucatán y México, que llevaron a la declaración de la independencia de Yucatán, con adopción incluso de un pabellón propio por parte de éste, ${ }^{3}$ tuvieron como correlato serios conflictos entre las distintas fracciones de la burguesía local representados en el antagonismo Mérida-Campeche. ${ }^{4}$ Estos conflictos tuvieron lugar mientras se producían en la región profundos cambios estructurales, que llevaron a Yucatán a pasar de una economía agricola tradicional a una economía de agricultura comercial de exportación: azúcar, tabaco, algodón, arroz, henequén y palo de Campeche, además de una naciente industria textil en Valladolid. Para 1847, muy pocas áreas de la región permanecían fuera de la economía de mercado.

2 El concepto de "tcrritorialidad" ha sido tomado de Carmagnani, "Territorialidad y federalismon, 1984, pp. 298-304.

${ }^{3}$ En las fuentes se menciona como "el pabellón verde de las cinco estrellas".

${ }^{4}$ A fines de siglo xvir se había hecho evidente la competencia entre el sector mercantil ligado al puerto de Campeche, y los nuevos comerciantes de Mérida y el puerto de Sisal. Desde entonces, los campechanos controlarían el comercio con Veracruz y los puertos del Gollo, mientras que la zona mercantil de Mérida estaría más ligada al comercio con Cuba. 
El objetivo de este artículo es estudiar los momentos en que Yucatán se vio envuelto en profundos conflictos internos y con el gobierno central, entre $1839-40$ y 1846 . Es dificil determinar en qué medida estos movimientos políticos fueron federalistas, autonomistas, o secesionistas, pero el propósito aquí será más bien analizar estos movimientos a partir de la proyección que ellos mismos se daban. Las fuentes hemerográficas brindan información tanto de los sucesos ocurridos, como de la manera en que se fue articulando en la población una cultura política de tipo liberal, y una tradición de participación y movilización política en torno a proyectos políticos que privilegiaban la dimensión local y territorial frente a la nacional.

Desde esta perspectiva, se podrían marcar dos momentos en lo que va de la historia yucateca entre 1840 y 1846 : el primero va de $1839-40$ y 1843 , desde la declaración de la independencia de Yucatán hasta la firma de los tratados entre México y Yucatán en diciembre de 1843, y el segundo, desde $1844-45$ a la nueva secesión en enero de 1846. Esos dos momentos se privilegiarán en este trabajo, pero no desde la perspectiva de lo que podría ser una "historia regional", sino más bien partiendo de la premisa de que la dinámica política de la territorialidad yucateca a mediados del siglo pasado estaba determinada por su relación con el gobierno central en México, y por su posición estratégica en relación con los intereses británicos y españoles. La articulación entre espacios locales y espacios metropolitanos en torno a conflictos puntuales de política interna, en un mundo que estaba dejando de ser colonial para transitar al neocolonialismo durante todo lo largo del siglo XIX, se producía en un momento de redefinición de las esferas de acción de viejas y nuevas potencias colonialistas. El caso de Yucatán -como en otro sentido lo fue Texas- es un excelente ejemplo de cómo la "territorialidad" de la primera mitad del siglo XIX permitió un ejercicio de las fronteras diplomáticas mucho más libre y complejo de lo que se verá más tarde, cuando el pacto interoligárquico e interregional daría lugar el Estado nacional de fines de siglo.

\section{EI. PRELUDIO}

En 1838, el jefe del Batallón tercero activo de Yucatán proclamó la federación en el pueblo de Tizimín, distrito de Valladolid, seguido de "sesenta o setenta hombres, los más desertores y algunos morenos idiotas del pueblo de San Fernando". 5 A partir de entonces, y a pesar de ser combatido por la Comandancia General del Departamento de Yucatán, y sus líderes encarcelados, el movimiento continuaría extendiéndose. 6

\footnotetext{
5 AGN, Gobernación, Sección Seguridad Pública, 1839; c. 179, 17, fol. 4: Carta del gobernador Pedro Marcial Guerra al Excmo. secretario de Estado y del Despacho de lo Interior.

6 Según Joaquín Baranda, "cl movimiento revolucionario contaba con un aliado poderoso, la opinión pública, que a veces constituye una fuerza poco ostensible, pero que al cabo se hace incontrastable, $y$ recorre, con más o menos prontitud el camino que conduce a la victoria". Baranda, Recordaciones, s. a., t. 1, p. 331 .
} 
El epicentro del movimiento se desarrolló en la ciudad de Valladolid, cabeza de un distrito donde la industria textil y azucarera estaba cobrando importancia por entonces. En esa ciudad Santiago Imán dio un manifiesto en febrero de 1840 , donde pedía el restablecimiento de la Constitución del estado sancionada en 1825 , la reposición de todas las autoridades constitucionales en funciones en 1834 , la instalación de una Junta Gubernativa Provisoria, y que el Congreso tuviese únicamente el carácter de convocante de uno constituyente. Al mismo tiempo, como recompensa a los servicios prestados a la causa y para reclutar más adeptos, Imán disponía en su manifiesto la abolición de las obvenciones que pagaban todos los indios varones a sus párrocos, táctica ésta que traería importantes consecuencias futuras. Unos días después, en la ciudad de Mérida -capital del departamento- se pronunció la guarnición local y gran número de simpatizantes, pidiendo el restablecimiento de la Constitución de 1824, la reunión de un Congreso General para reformarla, la reposición de las autoridades de 1834 y de las leyes que regían entonces, y la derogación de las leyes expedidas por el Congreso central, particularmente las que imponían contribuciones y gabelas. Finalmente, los insurrectos declararon inde pendiente al estado de Yucatán del gobierno de México, mientras éste no volviese al orden federal al amparo de la mentada Constitución federalista de $1824 .^{7}$

${ }^{7}$ Ancona, Historia de Yucatán, 1917, t. III, p. 328.

EL FEDERALISMO EN YUCATÁN
El gobernador Ernesto Cosgaya, y el vicegobernador Santiago Méndez, fueron las nuevas autoridades departamentales establecidas en Mérida. El plan de los insurrectos había triunfado, excepto en Campeche, donde aún resistían las tropas de la comandancia general. Finalmente, en agosto de 1840 la plaza de Campeche capituló.

La Legislatura local "reasumió" las facultades del Congreso General, y llamó a elecciones, por las que resultaron electos: gobernador, Santiago Méndez, vicegobernador, Miguel Ângel Barbachano, senadores propietarios, Manuel José Peón, José María Meneses, Juan de Dios Cosgaya y Mariano Brito. ${ }^{8}$ La nueva Legisiatura del estado iniciaría un arduo trabajo de discusión constitucional que la llevaría a la redacción de un "Proyecto de Bases para la Regeneración Política de la República, presentado a la Legislatura de Yucatán por su Comisión de Reformas", y un "Proyecto de Constitución presentado a la Legislatura de Yucatán por su Comisión de Reformas para la Administración Interior del Estado" durante el año 1841.

\section{EI. CONFIICTO ENTRE 1840 Y 1841}

El movimiento político yucateco de este periodo fue estudiado cuidadosamente por los primeros historiadores de Yucatán: Eligio Ancona, Joaquín Baranda, Albino Acereto. Las razones que ellos encuentran para la explosión del mismo son múltiples y complejas, y de algún modo serán dis-

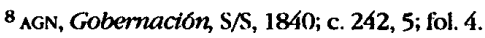


cutidas en este trabajo. Sin embargo, interesa aquí reflexionar sobre la mirada que un historiador de la talla de Howard Cline presenta sobre el mismo. Este autor, en un artículo pionero del año 1948, "El episodio azucarero, 1825-1850", sostiene que "[...] En la confusa y desordenada situación politica de entonces se reflejaba el cambio radical que estaba sufriendo la economía provinciana [...]"9 Estos cambios se relacionaban con la reorientación, contemporánea de los cambios en los mercados internacionales y de las guerras de la independencia, de la actividad económica de la provincia hacia la industria textil, azucarera y henequenera, en detrimento de producciones más tradicionales, como eran la madera, el ganado, los cueros, el jabón y la cera. Cline sostiene que:

la sierra azucarem, y sus asociados, los centros de destilación, sostuvieron abiertamente la revolución federalista de 1839 y después de ésta la primera guerra federalista contra México. Los gobiernos centralistas habían promovido una legislación contraria a los intereses azucareros... Como comenzaba a vislumbrarse la posibilidad de exportar azícar, las regiones cañeras favorecían denodadamente la completa independencia de México, evitando así la posibilidad de una legislación nacional contraria a sus intereses, $y$ afìrmando por otra parte su influencia en la Legislatura local. ${ }^{10}$

9 Cline, "El epidosio azucarero", en Pérez Betancourt y Ruz Menéndez, Yucatán, 1988, p. 216.

10 Ibid., p. 325.
Aunque este trabajo no ha estado orientado a verificar las hipótesis de $\mathrm{H}$. Cline, aquí se sostiene que los movimientos yucatecos de secesión politica frente al gobierno central no se explican solamente por problemas de indole económica, como lo fueron los del comercio de cabotaje y de exportación, o las tarifas arancelarias que se imponían a Yucatán al igual que al resto de los departamentos desde la Constitución de $1824 .{ }^{11}$ Fue decisiva además, en el desarrollo del conflicto, la especial visualización que los yucatecos tenían de la forma que debía adoptar a nivel constitucional la relación entre el gobierno federal y los estados. La discusión política que antecedió en Yucatán al estallido de la guerra de castas, estuvo orientada a

11 El único comercio que podía ejercer Yucatán cra el marítimo, y éste era afectado por aranceles que trataban a las embarcaciones yucatecas como navios extranjeros. Un reglamento de comercio de 1778 estableció el pago de derechos de importación y exportación según el "estado de necesidad" relativo de cada región, benefíciando a Yucatán con una tarifa de $11 \%$ para efectos españoles y un $4 \%$ para los de otra procedenciáa. La constitución de 1824 dejó en manos del Congreso General la habilitación de aduanas, el comercio con el extranjero y entre los diferentes estados de la federación (título III, sección v, art. 49). En 1827 se concedió, atendiendo a la especificicidad de la situación yucateca, la rebaja de dos quintos de los derechos de arancel a los efectos extranjeros. En 1837, esta ventaja se derogaría, junto con el establecimiento de una fuerte centralización administrativa por efecto de la vigencia de la Sexta ley Constitucional y de la Ley reglamentaria del Congreso Centralista de 1837 , que decretó que la mitad de las rentas de los departamentos se invirtiera en los gastos de éstos, y la otra mitad pasara a manos del supremo gobierno para gastos de la nación. 


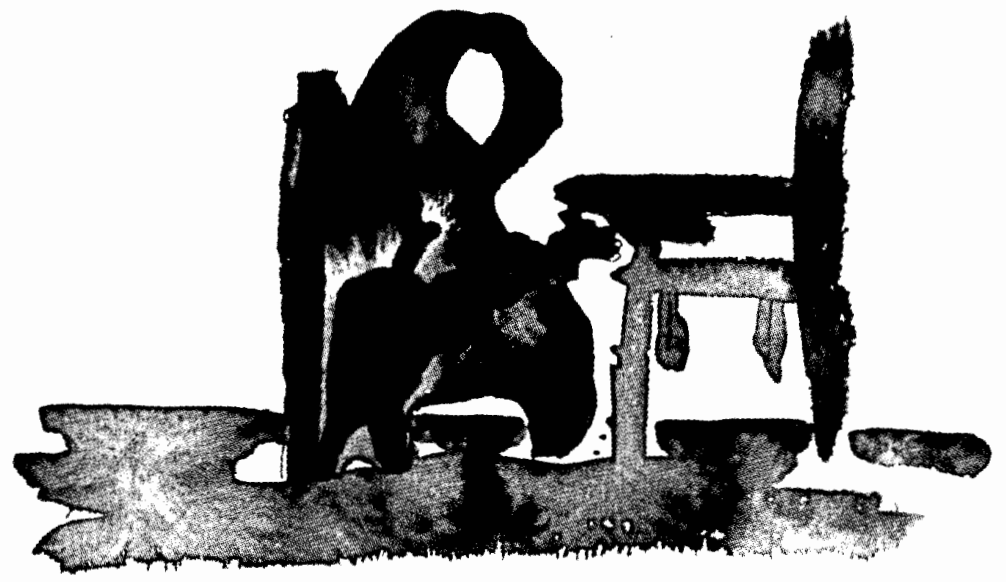

una redefinición de la relación política y administrativa que tenía esta península con el gobierno nacional y el resto de los estados.

En este sentido, la centralización administrativa que impusieron las Siete Leyes provocaron una reactualización de las discusiones de décadas anteriores. ${ }^{12}$ Las discusiones políticas se concentraron fundamentalmente en la definición de la conceptualiza-

12 La sexta ley constitucional establecía que los departamentos iban a ser gobernados por un gobernador nombrado por el gobierno general, a propuesta de las juntas departamentales, las que se conformaban por elección popular. Además se establecía en cada departamento, un jefe superior de Hacienda nombrado por el gobierno general. Las juntas departamentales reemplazaba a las legislativas estatales. ción constitucional del polo de la autoridad a nivel nacional y local -a través de la definición de las atribuciones de poder de uno y otro en el marco de un régimen federal y no unitario, como puede apreciarse en los tratados de 1841 y $1843-$, y del polo de la libertad del pueblo -a través de las discusiones sobre la representación popular. Así, es posible afirmar que, en el fondo del conflicto entre Yucatán y el gobierno general, no existió únicamente una discusión sobre atribuciones fiscales y arancelarias del gobierno nacional y los estados, sino también la afirmación de la autonomía política y administrativa de este estado, lo que puede verse claramente en los documentos constitucionales discutidos entre enero y 
julio de 1841 en la Legislatura local, renovada en agosto de 1840. En la declaración de la independencia de enero de 1841, por ejemplo:

[...] mientras no se acepte por el estado el nuevo código fundamental que se dicte para regir en lo sucesivo a la república, debe éste permanecer substraído de cualquiera gobierno general que se organice [...] En tal concepto [...] Art. 1: El estado de Yucatán no entrará por ningún orden de cosas, en que no se le reconozca constitucionalmente el derecho indispensable que le asiste:

1o. Para arreglar su administración interior $[\ldots]$

2o. Para determinar sobre materias religiosas [...]

30. Para no admitir en su territorio comandante general ni particular, ni más milicia que la que organice, ni que ésta se le saque total ni parcialmente [...]

40. Para administrar sus aduanas marítimas y aprovecharse de sus productos $[\ldots]$

5o. Para no contribuir a los gastos generales de la república [...]

7o. Para no sujetarse en lo demás sino a disposiciones libremente discutidas y dictadas por un Congreso nacional compuesto de representantes popularmente elegidos, y en que cada estado, provincia o departamento tenga una representactón igual... ${ }^{13}$

En el "Proyecto de Bases para la Regeneración Política de la República..." del 14 de enero de 1841, los diputados yucatecos estimaron refiriéndose a la Constitución de 1824, que:

13 BN, col. Lafragua, vol. 298, pp. 19-20.
[...] el defecto principal del código referido, consiste en la mala distribución del poder nacional, en el general de la república y el particular de los estados...

Tal fue y era natural que fuese la funesta consecuencia del inmenso poder acumulado en el gobierno general por la mencionada constitución

¿Qué hacer pues para conciliarle de nuevo el aprecio general...? [...] Debilitar la administración de la unión, y estableccr el justo y conveniente equilibrio que debe haber entre los poderes de ésta y los que se otorguen a los estados, para que puedan tranquilos atender a sus respectivas necesidades $[\ldots]^{14}$

La misma idea se expresaba en el periódico local:

[...] Ya hemos dicho, y no nos cansaremos de repetir, que las leyes que se dan sólo a la vista de lo que conviene al rico y opulento departamento de México, no pueden ser adaptables y benélicas a los departamentos pobres como el nuestro $[\ldots]$ y ahora es tiempo de que a

14 "Proyecto de Bases para la Regeneración Política de la República presentado por la Comisión de Reformas de Yucatán, Mérida, 14 de enero, $1841^{\prime \prime}$, en BN, col. Lafragua, vol. 298; pp. 5,7 y 15 . Entre los veinte diputados propictarios clegidos en 1840 que votaron estos proyectos de reforma constitucional se encontraban: Manuel Crescencio Rejón -supuesto autor intelectual de éstos- por Mérida; por el particlo de Valladolid, junto a otros dos, Pedro Regil; por Izamal Crecencio Pinclo, Isidro Rejón y Pedro Rivero; por el partido de Ichmul Antonio García Rejón entre otros dos más. La familia Peón se hallaba representada en la diputación de Teabo y de lchmul. aGN, Gobernación, s/s, $1840 ;$ c. 242,5 , fol. 8 . 
cada uno se atienda según sus necesidades $[\ldots]^{15}$

Por supuesto, el problema de las aduanas y aranceles no se excluía de estas consideraciones. ${ }^{16}$

Esta búsqueda de autonomía administrativa, expresada en la idea de "debilitar la administración de la unión", también se aprecia en los artículos del "Proyecto de Bases para la Regeneración política [...]" que hacen referencia a la existencia de comandancias generales -rechazadas terminantemente por estar subordinadas a las necesidades del gobierno de la unión y no a las del gobierno departamental. Al mismo tiempo se destaca la importancia que da este proyecto (y que sobresale igualmente en el Proyecto Constitucional de 1841) a la posibilidad de establecer la libertad de cultos, como forma de promover lo colonización y el progreso económico y comercial de la región. Y es en este

is Desde Mérida, artículo reproducido en el Diarto de Gobierno, 28 de febrero de 1840, p. 1 , col. 2.

16 El "Proyecto de Bases..." arriba citado, decía, refiriéndose al problema de la centralización administrativa: "[...] se vería expuesto el estado a sufrir el establecimiento de esas aduanas interiores... y los yucatccos oprimidos por gabelas malamente calculadas y pésimamente distribuidas por falta de conocimiento del estado de su industria y de sus demás circunstancias peculiares". BN, col. Lafragua, vol. 298, p. 15. De hẻcho, el comercio yucateco se vería inmediatamente afectado con todos estos sucesos, pues el 17 de julio de 1841, la presidencia declaró bloqueados los puertos yucatecos y los efectos de ese origen en los demás puertos mexicanos. AHSRE, "Disposiciones sobre buques, comercio y actos de las autoridades rebeldes de Yucatán", 6-869/1840-1849, 17 de julio de 1841, fol. 6 . punto donde se define con claridad cuál era la forma de organización política que estaban proponiendo los yucatecos:

¿No hubiera sido más útil y más conveniente que se hubiese dejado el arreglo de esta materia a cada estado, que habría obrado entonces conformándose con sus especiales circunstancias, $y$ no reservarlo exclusivamente a la administración de la unión, que no podía dictar una medida general sin ofender intereses de importancia y trascendencia? ${ }^{17}$

Es la descentralización administrativa lo que se busca. Y ésta puede, conjugarse igualmente con el poder político federal, derivado de la representación "legítima" de las diputaciones estatales en el Congreso de la Unión, pero bajo la forma de un estado mínimo de tipo confederalista, en el que se buscaba conservar una administración central con jurisdicciones mínimas frente a una amplia autonomía estatal fuertemente fundada sobre la base de la soberania territorial. La propuesta de los yucatectos relativa al derecho de representación departamental en el Congreso Nacional también indica una manera de visualizar las relaciones políticas y administrativas entre los estados: se propone una representación igualitaria para todos los estados miembros de la república federal -igualdad de representación con que cada uno debe concurrir a la organización de la república-, eliminando de este modo el concepto de representación propor-

17 BN, col. Iafragua, vol. 298, p. 11. 
cional a la población, aunque en el proyecto de constitución del mismo año se mantiene ese principio a nivel estatal. ${ }^{18} \mathrm{Al}$ mismo tiempo, los diputados no se concebían como representantes universales del pueblo, sino como "representantes yucatecos" cuya misión era la defensa de unas instrucciones determinadas previamen. te, lo que demuestra la articulación de ideas de vieja tradición con otras de neto corte liberal.

Redactadas cuando Yucatán se encontraba separado de la Unión, lo más significativo en estas propuestas de reforma constitucional es su reconocimiento de las instancias constituyentes como medio para reconstituir y reformar el orden político e institucional. Sin embargo, este reconocimiento va unido a una negación del polo de la autoridad central nacional: mientras no se reformase la Constitución vigente, Yucatán permanecería sustraído de la república. ${ }^{19}$

En términos generales, todas las propuestas y demandas de Yucatán relativas a la reorganización de las relaciones gobierno nacional-gobierno departamental delineadas en 1840-41, fueron las que este mismo estado levantó como reivindicación entre 1841 y 1846: en las negociaciones con Andrés Quintana Roo en noviembrediciembre 1841, en la firma de los acuerdos de diciembre de 1843 con el gobierno nacional luego de un perio-

18 "Proyecto de Constitución presentado a la Legislatura de Yucatán por su Comisión de Reformas para la administración interior del estado, 15 de enero de 1841", en Planes de la Nactón, 1987, lib. v, pp. 12-18.

19 Ibid., p. 20. do de enfrentamiento armado, y entre febrero de 1844 y fines de 1846 . Sólo que la manera en que se argumentó alrededor de las mismas fue haciéndose más radical, por un lado, y más intransigente, por otro. En esto tuvo innegable influencia la guerra que llevó Yucatán durante más de un año contra las tropas del gobierno nacional, la cual provocó un aumento en la participación del pueblo, no sólo en las milicias, sino también en la discusión sobre la forma constitucional más conveniente a la organización nacional, y sobre la manera en que Yucatán debía -o no-integrarse a la república mexicana.

En la paulatina generalización de la participación popular tuvo influencia determinante el "Proyecto de Constitución presentado a la Legislatura de Yucatán [...] para la administración interior del estado" del 14 de enero de 1841, y la Constitución aprobada el 31 de marzo de 1841.

Estos documentos constitucionales establecieron las elecciones populares directas para diputados y senadores de la Legislatura local, ampliando la base electoral al no imponer distinción de raza, riqueza o alfabetización al ejercicio de la ciudadanía. Esste fue un cambio importante porque desde la Constitución de Cádiz, modelo de reglamentación electoral en la primera mitad del siglo XIX, la constante había sido la elección indirecta de los representantes y autoridades. ${ }^{20}$ Sin embargo, se mantuvieron criterios censitarios (de riqueza) para

20 "El nombramiento de representantes por electores intermedios no es verdaderamente 
delimitar el universo de los ciudadanos elegibles para diputados, senadores y gobernadores, por lo que la base electoral, si bien ampliada por la nueva delimitación del universo de la ciudadanía, fue simultáneamente restringida al establecerse una selección censitaria de los ciudadanos aptos para desempeñar cargos electivos.

Estas disposiciones resaltan el correlato entre guerra y política de los negocios públicos yucatecos, por la vinculación entre movilización militar y ampliación de la ciudadanía, pues al incorporar a ésta la población indígena (el $70 \%$ de la población del estado) se garantizaba la conformación masiva de la milicia.

Existen también indicios de que en julio de 1841 el gobernador Santiago

popular porque ni los electores pueden recibir instrucciones especiales de sus respectivos comitentes, para nombrar a las personas que sean de confianza de éstos, ni aunque pudiesen recibirlas por la divergencia de las voluntades de los votantes, que los hubiesen revestido de poder electoral [...] Así es que frecuentemente se ve en las elecciones indirectas [...] que se desnaturaliza una representación verdaderamente democrática [...] apoyada la Comisión en la razón y la experiencia, no ha vacilado en consultaros la adopción de las elecciones populares directas, proponiéndoos al efecto, que los diputados y senadores que hayan de componer el poder legislativo del estado, sean elegidos inmediatamente por el pueblo dividiéndose para ello las parroquias en secciones que consten de 1000 y 2000 almas, y en que cada ciudadano nombre los representantes que le merezcan su confìanza [...]" "Proyecto de Constitución presentado a la Legislatura de Yucatán por su Comisión de Reformas para la administración interior del cstado, 15 encro de 1841", en Planes en la Nactón, 1987, lib. Iv, p. 12-13.
Méndez pidió a la población que emitiera su opinión respecto de la independencia definitiva, mecanismo que se utilizó continuamente entre 1845 y 1846. ${ }^{21}$ Esto indica que el enfrentamiento con México provocó un doble juego: amplió la difusión e institución constitucional de la doctrina liberal, pero al mismo tiempo revitalizó prácticas institucionales de raigambre colonial, que implicaban la representación estamental además de la ciudadana, al reactualizar, por medio de las convocatorias a cabildos abiertos o juntas, la legitimidad soberana de los ayuntamientos frente al poder ejecutivo y legislativo estatal.

En medio de esta movilización popular y de las elites, el gobierno mexicano, irónicamente, dependía de las noticias que le llegaban desde Cuba, de sus contactos en La Habana a través de su Consulado. Y desde el comienzo del problema, Cuba, como uno de los últimos reductos del poder español en América, jugaría un ambiguo papel, tanto para el gobierno central como para los mismos yucatectos, ${ }^{22} \mathrm{e}$ iniciada la guerra, tanto Cuba como los británicos de Belice intervendrían en ella. ${ }^{23}$

21 AHSRE, "Documentos referentes a la subversión ocurrida en Yucatán, con motivo de su pretensión de independizarse del gobierno mexicano" ${ }^{n}, 3-3-4025 ; 1841$, fols. 5-6.

22 AHSRE, "Noticias que comunica el cónsul mexicano en La Habana, sobre los sucesos políticos, en el departamento de Yucatán", 3-34020, 1841, 25 fols.

23 Great Public Record Office, General Correspondence, F.O. 50, 128. 
III. GUERRA Y POLITICA EN BUSCA DE LA NEGOCIACIÓN

Los preparativos para el enfrentamiento armado comenzaron a mediados del año 1841. El gobierno nacional, además de bloquear los puertos y productos de Yucatán, hizo valer internacionalmente su representación de la nación mexicana, comunicando que consideraría acciones de guerra, o contrabando de guerra, el no cumplimiento de las naciones amigas del bloqueo a Yucatán. ${ }^{24}$ En México se tenían noticias de que los yucatectos habian enviando comisionados a Francia y a Estados Unidos para que fuese reconocida su independencia.

Pero gracias a los informes y asesoramiento que se recibían desde el Consulado de Cuba, Santa Anna decidió enviar un comisionado de paz y negociación antes de entrar en operaciones armadas. El espectro de Texas, no sólo por el conflicto al norte, sino por las relaciones amistosas de cooperación entre Texas y Yucatán, ${ }^{25}$ espantaba a los políticos y militares del

24 Esto es claro en el caso de Cuba y España, pues allí se recibían los productos yucatecos, incluso en embarcaciones de ese departamento. Dispuesto a no permitir nada "que pueda afectar de cualquier modo que sea la nacionalidad de la república, su independencia y la integridad de su territorio, del que forma una parte dicho departamenton", el gobierno nacional declaró nulos todos los pactos que Yucatán pudiese realizar con otras naciones, sea cual fuera su naturaleza. AHSRE, "Disposiciones sobre buques", 6-8-69/1840-1849, 11 de agosto de 1841, fol. 2-5.

25 Comentarios sobre este asunto aparecen en El Cosmopolita, 26 de marzo de 1842, pp. 1 y 2. El mismo Quintana Roo fue capturado por una fragata texana, que había sido inicialmente centro. Llegado Quintana Roo, luego de arduas negociaciones, se firmó un acuerdo de reintegración a México, el cual resultó rechazado por el gobierno central, "[por]que se presenta en él ese departamento como una nación soberana que hace con el resto de la república, no una parte integrante de ella, sino una aliada ${ }^{n} .{ }^{26}$ En él se pueden apreciar cumplidas todas las reivindidaciones de Yucatán, relativas a autonomía administrativa, aduanera y militar, excepto en el caso de los funcionarios de aduana, que serían nombrados por el presidente sobre una terna presentada por el gobernador. Fracasada la embajada de Quintana Roo, se inició la guerra.

Los yucatecos contrataron embarcaciones texanas, compraron buques en Nueva Orleáns, y también más de un ciento de cajas de fusiles en La Habana ${ }^{27}$ La Legislatura local convocó a contribuciones extraordinarias en la población (entre septiembre y diciembre de 1842 se dieron en conjunto 25 leyes y decretos que disponían empréstitos de guerra, préstamos forzosos, y exenciones impositivas a los movilizados), se organizaron las mili-

contratada por los yucatecos como apoyo a su marina. Se puede seguir la misión Quintana en AGN, Gobernación, Yucatán, 1841, c. 247, 1.

26 "Manifiesto del gobierno provisional a la nación acerca de los negocios de Yucatán", 1843 ; p. 35 . BN, col. Lafragua, vol. 869.

27 El gobierno mexicano protestaba a través de su consulado en Ia Habana, y de su delegación en España, respecto de la libre entrada de buques campechanos en el puerto de La Habana, y del continuo tráfico de armas de guerra entre Cuba y Yucatán. "Noticias que comunica cl Cónsul Mexicano en La Habana", AHSRE, 3-3$4020,1841$. 
cias cívicas (enero de 1841 y 22/11/42) y se decretó la expulsión de los opositores en favor de su seguridad personal $(25 / 2 / 43)$. También se organizaron guerrillas ciudadanas desde el 28/3/43. ${ }^{28}$

A partir de este momento, la participación de los ciudadanos en la guerra como milicia ciudadana incorporaria un elemento de mayor popularidad a los negocios públicos. Los indigenas yucatecos fueron llevados a la guerra, y un discurso "patriotero" $y$ politizador daria fundamentación a esta movilización masiva. ${ }^{29}$

Nuevamente, se garantizaría la ampliación del sistema político como una forma de asegurar la conformidad del pueblo frente a la situación de guerra. ${ }^{30}$ Así que, cuando Yucatán venció a las tropas mexicanas -que no pudieron tomar Campeche-y México ofreció nuevamente la pacificación aceptando firmar unos convenios similares a los de diciem-

28 Aznar Pérez, Colección de leyes 1850 , t. II.

29 "Si, compatriotas, uno de los mejores y más seguros baluartes de la libertad es la milicia ciudadana; con ella los Estados Unidos de Holanda sacudieron la intolerable tiranía de España [...]: con ella la república francesa supo triunfar de todos sus enemigos [...] ¿ :Pero para qué más ejemplos?, inecesitamos acaso entusiasmar a nuestros defensores? [...] jOh patria! tú eres mi único objeto, $[\ldots]$ y juro de hacer mi parte cuanto sea posible, bien unido con mis conciudadanos [...]para que jamás llegues a ser tiranizada en ninguna manera, ni sufras opresión. Un Yucateco". El siglo diez y nueve, 10 de septiembre de 1842 , p. 4 .

30 "Al Congreso Yucateco [...] Tan mágico poder tiene hoy la representación del estado que, desde el supremo jefe del poder ejecutivo hasta el último y más ignorante indigena de los campos, se sienten vivificados en su espíritu, bre de $1841^{31}$, el gobernador de Yucatán, Santiago Méndez, dispuso en noviembre 25 de 1843 una consulta a todos los pueblos, "para cerciorarse de cuál sea la opinión al respecto de la mayoria sus habitantes, para respetarla y proceder $[\ldots]^{n}$. Ordenó que las municipalidades convocaran a la lectura y discusión de los documentos relativos a la propuesta mexicana de reincorporación de Yucatán a la república, a "capitalistas y propietarios, y a todos los demás vecinos de la comprensión de esa municipalidad, que sepan leer y escribir[...]" Los convocados debían firmar respondiendo si/no. ${ }^{32}$

cnardecidos en sus determinaciones y fuertes en su voluntad para cuanto pida la salvación de la patria y sus derechos con sólo verlos reunidos otra vez. Jamás fue tanta verdad la representación de una comunidad en un Congreso, como lo es hoy en Yucatán [...] No hay más que un objeto para todos: la libertad, un sólo camino por donde alcanzarla, la guerra; una disposición única para hacerla con vigor y obstinación. El pueblo se encuentra con vosotros para la realización de la cmpresa, vosotros con el pueblo para la realización de los designios $[\ldots]$ Yucatán es invencible, ilustres diputados!", El stglo diez y nueve, 6 de septiembre de 1842, p. 3 .

31 Lo que, para el plenipotenciario español en México era como otorgarle a Yucatán "una independencia casi absoluta en su gobierno interior". AHSRr, Correspondencia del ministro de España en México, Pedro Pascual de Oliver, con el primer secretario del Despacho de Estado, Conde de Almodóvar, 1842-43, despacho 282, "Sobre los últimos sucesos del Yucatán y el posible arreglo de sus diferencias con México por la firma de la paz, 24/6/1843", p. 2.

32 Una convocatoria de este tipo, y con idénticos resultados de masividad, volvería a repetirse en ocasión del desconocimiento por parte del Congreso General de los convenios del 43, en diciembre de 1845, antes de producirse la segunda secesión. Ver más abajo. 
El fundamento explícito de estas medidas era la necesidad de acercarse a un conocimiento más exacto de la verdadera opinión de la mayoria del estado". .33 Si bien la consulta se llamaba sólo para los alfabetos, en los pequeños ayuntamientos del interior participaban los indios y sus repúblicas, y gente que no sabía leer ni escribir, pues un escribano firmaba en su nombre.

Esta política de apertura a la participación generada desde el polo de la autoridad-pero que indudablemente respondía a la presión de los representados, una población movilizada por la guerra- crearía, por un lado, ineludibles compromisos políticos de las autoridades con los pueblos; y por otro, una conciencia de participación política en la población que no sería fácil de controlar y limitar una vez generada.

Si bien esta apertura pudo formar parte de una estrategia defensiva de la elite política yucateca, revela, por un lado, la permeabilidad de ésta al constitucionalismo liberal y, por otro, la incorporación de los sectores populares al universo de discusión política, a través de su incorporación a las milicias $\mathrm{y}$ al debate político local. ${ }^{34} \mathrm{Asi}$ mismo, implica la revitalización de prácticas de raigambre colonial, que reforzaban la representación estamental además de la ciudadana ampliada por la Constitución: la conso-

${ }^{33}$ El siglo diez y nueve, 20 de diciembre de 1843 , p. 2.

${ }^{34}$ Participación alentada indistintamente en blancos e indios, al menos en lo militar. lidación del poder del ejecutivo provocada por la guerra en Yucatán, como proceso de reforzamiento del polo de la autoridad al interior del estado, exigió la legitimación y negociación constante frente a los ayuntamientos, cuerpos políticos representantes de las libertades de los pueblos de la península.

Producto de la victoria yucateca y consecuentes con el bando vencedor en la guerra, los tratados de 1843 no sólo otorgaron a Yucatán la libre organización de su régimen interior -lo que equivalía a autorizar cualquier tipo de régimen político-, la libre administración de sus rentas, y la libre determinación de su comercio interno y externo, sino también la libertad para organizar el ejército (art. 5) y para colaborar con tropas, exclusivamente en caso de guerra exterior. Sin embargo, Yucatán se aseguraba de que

siempre que en casos extraordinarios se vieren alterados la tranquilidad y el orden en Yucatán, y sus autoridades solicitaren del supremo gobierno el auxilio de alguna fuerza, se le concederá sin demora.

La mayoría de las disposiciones del convenio, respondieron de este modo a las demandas yucatecas de 1840-41: no más problemas arancelarios, nn más dependencias del gobierno nacional a través del representante de Hacienda y del comandante general, no más sangría de yucatecos a través de levas extraordinarias para la guerra de Texas. 


\section{EN BUSQUEDA DE UNA NUEVA RELACIÓN}

Los tratados de diciembre de 1843 se convirtieron al poco tiempo en la piedra del escándalo: para los políticos del México central, porque equivalia a otorgar a Yucatán un estatus de nación asociada; para los yucatecos, porque a poco más de un mes de su firma, el gobierno central dictó un régimen arancelario específico para Yucatán, que infringía la libre aceptación y circulación de los productos yucatectos en todos los puertos mexicanos, art. 11 del tratado, y que perjudicaba profundamente sus posibilidades de inserción en el mercado mexicano. ${ }^{35} \mathrm{Y}$ porque un año después, el 13 de di-

35 El 21 de febrero de 1844, el ministro de Hacienda y el gobierno general dictaron una ley arancelaria específica, con el objetivo de "dispensar a la industria nacional todo eramparo y la protección que necesita para su desarrollo y engrandecimiento, ha considerado como una de las medidas más indispensables para llenar aquel objeto, designar las producciones del departamento de Yucatán que, conforme al articulo 11 de los tratados celebrados en 14 de diciembre último, han de admitirse en los demás puertos de la república, con el fin de evitar cualquier abuso que quisiera intentarse para introducir articulos y manufacturas extranjeras, como procedentes del referido departamento..." Las producciones que se excluyeron del comercio yucateco con México fueron: aguardiente común, azúcar, algodón, carne de puerco, cigarros, manta cruda, hilo de algodón, jabón, panela, pescado seco, tabaco en rama, cueros, entre otros. En "Exposición del Gobierno de Yucatán al Supremo de la República pidiendo la derogación del decreto de 21 de febrero último, Mérida, 1844" y "Exposición que dirige al Soberano Congreso Nacional el Gobierno del Departamento de Yucatán, Mérida, 1845", BN, col. Lafragua, vols. 453 y 299. ciembre de 1845, el Congreso de la Nación, revisando lo actuado por la administración santannista, se negó a ratificar lo convenido con Yucatán en 1843.

Muy pronto se entabló una fuerte polémica entre Yucatán y México al respecto, especialmente a partir de diciembre de 1845, cuando la Comisión ad hoc del Congreso revisó el tratado. ${ }^{36} \mathrm{Y}$ al calor de ésta, y de los continuos reclamos de los diputados yucatecos en las Cámaras, Yucatán fue perfeccionando sus argumentos, incluso legitimando la rebelión de 1840 como "el restablecimiento de la Constitución de 1824: proclamó, pues, el restablecimiento de los principios y el imperio de las leyes. ${ }^{37}$

Los yucatecos sostenían que no habían pretendido separarse de México como los texanos porque, habiendo vencido la guerra, igualmente optaron por reincorporarse a la nación mexicana. En todo su discurso resurgió permanentemente un argumento que apenas había incidido en las discusiones de 1841-43: el de la "especificidad" de Yucatán: cultural, geográfica, histórica y étnica, la cual hacía necesario, desde la perspectiva de los yucatecos, un trato "diferencial" para Yucatán en relación con el resto de los estados de la Unión. El trato diferencial se convirtió en el principal recla-

\footnotetext{
36 Es el caso del debate entre El siglo diez y nueve de México y El siglo diez y nueve, periodico oficial del departamento de Yucatán.

37 "Exposición que dirige al Soberano Congreso Nacional el Gobierno del Departamento de Yucatán. Mérida, 1845", p. 3. BN, col. La Fragua, vol: 299.
} 
mo y argumento de los yucatecos, quienes encontraban en la colonia las raices del mismo: el tratamiento diferencial que habían dado a Yucatán las reformas borbónicas. ${ }^{38}$

Los yucatectos avanzaron en su argumento amenazando con la independencia si no eran satisfechos en sus demandas. En este contexto discursivo, los convenios de diciembre dejaron de ser acuerdos de reincorporación para convertirse en un reconocimiento de la especial condición de Yucatán para los yucatecos, reconocimiento que había tomado la forma casi de un acuerdo entre naciones en el discurso de la diputación peninsular.

Mientras el gobierno nacional sostenía, ya desde la misión negociadora de Andrés Quintana Roo, que "la naturaleza de las cosas es superior a todo pacto", partiendo de la original "integridad territorial", los yucatecos sostenían que la soberanía del estado era superior $y$ anterior a todo pacto o acuerdo de integración territorial. Si éste era violado por una de las partes -en el caso de los acuerdos del 43, por México-, era una cuestión de derecho internacional que podía derivar en un conflicto; pero que liberaba mientras tanto a Yucatán de toda obligación respecto de México:

38 Incluso se preguntaban, intentando fundamentar su pretensión: iqué dirían los mexicanos si España pretendiera uniformar la administraciốn de Cuba a la de las otras provincias del reino?, "Obscrvaciones sobre la actual situación política del departamento de Yucatán, México, 1845", p. 17. BN, col. Lafiragua, vol. 71.
[...] E] derecho de gentes, reconocido por todas las naciones del mundo civilizado, [...] según él, cualquiera sea la suerte del supremo magistrado que firmó el contrato, se estima hecho a nombre de la nación que representaba [...] Las naciones y jefes deben cumplir religiosamente sus promesas y tratados [...] Cuando el jefe de una república hace un tratado, la nación misma es la que contrata, y sus obligaciones no dependen de la vida o duración en el gobierno del que ha sido firmante [...] México no sólo ha fáttado a una condición al todo del contrato [...] luego ya no existe pacto de unión; luego Yucatán ha reasumido su soberanía radical y primitiva, como cuando se hizo independiente del gobierno español [...] luego puede constituirse como pueblo soberano e independiente [...] El pensador Yucateco. ${ }^{39}$

El Congreso respondía que era inadmisible que Yucatán considerara el acuerdo como un tratado internacional: primero, porque Yucatán era un departamento, no una nación independiente, y segundo, porque aunque así fuese, el Congreso, y no el ejecutivo, era quien tenía la facultad de convertirlo en ley ratificándolo o reprobándolo. Se preguntaban las co-

39 El siglo diez y nueve, 5 de febrero de 1846, pp. 3 y 4 . Los diputados y representantes yucatecos en México, sin embargo, desmentían que el tratado fuera un tratado de alianza - cosa que se argumentaba en Yucatán-, y sostenían que "no es más que un arreglo eficaz para remover graves inconvenientes que cl tiempo, las desgracias y la experiencia han demostrado", "Observaciones sobre la actual situación política del departamento de Yucatán", BN, col. Lafragua, vol. 71, p. 13. 
misiones de Hacienda y de Gobierno, encargadas de la revisión:

Si tal principio llegara a adoptarse en la política de México, muy poco faltaría para que algún departamento aspirase también a celebrar tratados con las naciones extranjeras, y entonces, ¿qué sería de la unidad nacional?, ¿qué organización política sería posible establecer en la república?. ${ }^{40}$

Era inadmisible además, desde la perspectiva de la organización administrativa nacional, que Yucatán contara con una fuerza armada permanente, sin sujeción al gobierno central, y que no contribuyera ni con hombres, ni con rentas, a los gastos del gobierno general. $Y$ su libertad para determinar los aranceles de importación y exportación podía llevar al comercio exterior a la pérdida de

todo su equilibrio y regularidad con enorme perjuicio de toda la nación, si los departamentos litorales pudieran dar leyes para arreglar los aranceles marítimos y modificar estas leyes como lo crean conveniente. ${ }^{41}$

El Congreso reconocía, de todos modos, el derecho a que Yucatán arre-

40 "Memoria de la Secretaría de Estado y del Despacho de Relaciones Interiores y Exteriores de los Estados Unidos Mexicanos, leída al Soberano Congreso Constituyente, por José María Lafragua. México, 1847", documento número 29, BN, col. Lafragua, vol. 509, p. 59.

41 "Memoria de la Secretaría de Estado y del Despacho de Relaciones Interiores y Exteriores de los Estados Unidos Mexicanos, leída al Soberano Congreso Constituyente, por José María Lafragua. México, $1847^{*}$, documento número 29, BN, col. Latragua, vol. 509, pp. 59, 60. glara libremente su administración interna, adecuándola a sus condiciones específicas y excepcionales, a través de una ley de excepción para su organización política, dictada por el Congreso a iniciativa del ejecutivo, como lo preveía la Constitución.

Enfrentados a este discurso, los yucatecos consideraban que, además de cuestionar la validez de los tratados, México intentaba perjudicar su industria con leyes arancelarias específicas que olvidaban la total dependencia yucateca del comercio de cabotaje con Tabasco y los puertos de la costa, de alli la terrible incidencia de esta medida para el comercio de ese territorio. 2

Más allá de la discusión puntual respecto al arancel específico del 21 de febrero de 1844 , interesa ver cuáles fueron las consecuencias en la dinámica de la política interna yucateca de toda esta discusión en torno a los tratados.

Luego de sucesivos reclamos en el Congreso y frente al supremo gobierno, el gobierno de Yucatán se decidió por hacer uso de los mecanismo de

\$2 La disposición arancelaria buscaba justifi. cación en el supuesto contrabando yucateco de productos importados, a través del comercio de cabotaje. Era indudable que Yucatán introducía mercancía británica desde Bélice (comercio al que estaban incorporados los indios como transportistas) y mercancía americana y cubana, a través de su comercio en el Caribe. Sin cmbargo, tanto las fuentes como el excelente trabajo de Howard Cline demuestran que Yucatán estaba en pleno proceso de expansión agrícola e industrial en la época, con una importante producción azucarera, henequenera y textil algodonera, lo que explica los reclamos yucatecos. 
consulta popular que se habían incorporado a la tradición política yucateca desde la guerra del 42-43. Así, el gobernador Miguel Barbachano, el 8 de diciembre de 1845, dispuso:

[...] El Excmo. señor gobernador, en estas circunstancias, ha creído conveniente inquirir y oír por medio de los ayuntamientos y municipalidades, cuál sea la verdadera opinión de los pueblos acerca de los indicados convenios, y si están o no, por la subsistencia, insubsistencia o derogación de ellos. Esta manifestación se exige sin coacción alguna y en el concepto de que pueden, sin temor de ningún cargo, emitir francamente y con plena libertad, su modo de pensar sobre este importante asunto... 43

A partir de este momento, todos los pueblos y ayuntamientos, al igual que los regimientos de artillería y policía -aunque no habían sido convocados a emitir su opinión- enviarían a Mérida los resultados de la consulta popular. Estos resultados aparecieron publicados en el periódico oficial de Yucatán. ${ }^{44}$

43 El siglo diez y nueve, 11 de dicicmbre 1845, p. 1 , col. 2.

44 Contamos con el resumen de las actas de las reuniones que tuvieron lugar en Mérida, El Carmen, Campeche, Tekax, Teya, Peto, Valladolid, Chemax, Espita, Izamal, Akal, Ticum y Bacalar, y con las declaraciones en torno al mismo asunto del Batallán 1o. y de la 1a. Brigada de Artillería de Mérida, de los Batallones 4o. y 5o. de policía de Valladolid, de la Segunda Brigada de Campeche, y de la Sección auxiliar de Oriente con sitio en Loche, aparecidas en $E l$ Siglo Diez y Nueve, entre diciembre de 1845 y marzo de 1846, en las fechas: $9,11,13,23,25$, 30 , de diciembre de $1845 ; 1,8,10,13,15,17$.
Las 19 actas que se han consultado ratifican la total adhesión a la subsistencia de los tratados, y demandan al gobierno provincial su defensa a ultranza. ${ }^{45}$ Esto indicaría, a simple a vista, la existencia de un sentimiento de pertenencia a México. Pero, sin embargo, se aprecia en los mismos una marcada animosidad hacia México, puesto que se repite continuamente la idea de que México desconocía la "excepcionalidad de Yucatán", y de que intentaba "tiranizar" a Yucatán imponiéndole sus leyes. En estos testimonios se pueden apreciar las consecuencias de los dos años de guerra en la conciencia política de la población: todos se niegan a retrotraerse a la situación previa a 1840 , pues eso significaría negociar la sangre yucateca caída. La experiencia de la lucha por la reincorporación, dentro de la nación mexicana, a un régimen de plena libertad administrativa y constitucional, no autorizaban una unión

$20,26,27$, de enero de $1846 ; 5,10,18,27 \mathrm{dc}$ febrero de 1846; 17 de marzo y 14 de abril de ese mismo año.

45 Los testimonios no presentan grandes diferencias en su discurso. Inicialmente pensé que los resultados de las consultas en Mérida y Campeche podía diferir sustancialmente de los del resto, al ser ciudades de una tradición política más antigua, y donde seguramente era mayor el porcentaje de población blanca. Sin embargo, sólo se puede apreciar una marcada diferencia en el discurso de los actos que corresponden a distritos eminentemente comerciales, como Bacalary El Carmen y los otros: en éstas, la preocupación no es ni la independencia ni los tratados ni las modalidades de unión: preocupa la continuidad de una actividad que conduce al progreso industrial y cultural, el comcrcio. El Siglo Diez y Nueve, 4 de abril de 1946, p. 1 y 11 de diciembre de 1945, p. 2. 


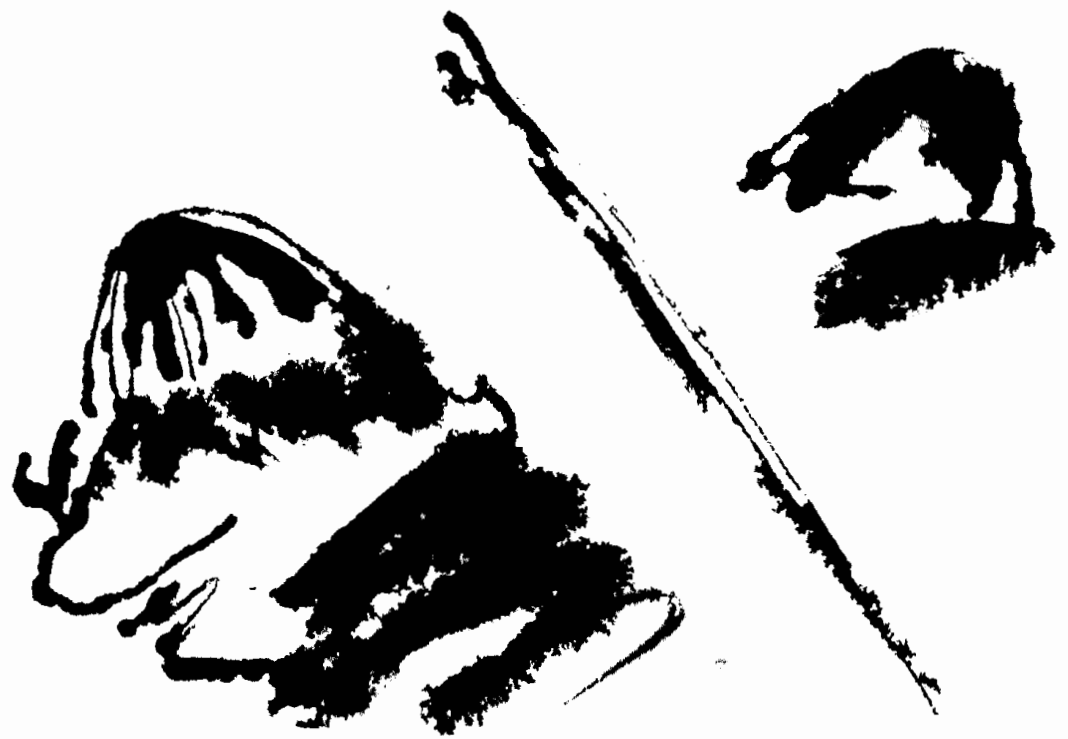

con pérdida de derechos para la libertad del estado yucateco. ${ }^{46}$

La experiencia de la guerra, su profunda incidencia como experiencia colectiva del pueblo yucateco, vuelve entonces inevitable la guerra para los yucatecos, en el caso de que los tratados que le dieron fin fuesen desconocidos o revocados. La independencia era el corolario de todos estos razonamientos:

[...] apurada ya la copa del sufrimiento, se haga $y$ se declare nuestra inde-

46 “ $[\ldots]$ De ninguna manera se podrín ver con indiferencia aquellos convenios sellados con la sangre de sus hermanos vertida en los campos del honor, cuyos indudables derechos eran hijos de su glorioso triunfo [...]", El siglo diez y nueve, 30 de diciembre de 1945, p. 2. pendencia absoluta del resto de la república, contando para llevarla a cabo cualquier clase de sacrificios que se pretendan hacer con aquel objeto, con los vecinos de este pueblo (pucblo de Ticum, partido de Tekax).

La guerra produjo consecuencias que serían definitivas con respecto a la organización política y a la distribución del poder político en la sociedad yucateca de mediados del siglo XIX. Tanto la participación de los indígenas en las reuniones de discusión de los tratados, como las comunicaciones emitidas por distintos regimientos yucatecos, demuestran cómo el sistema político fue abriéndose cada vez más durante los seis años de problemas con México. 
De los 19 testimonios consultados, siete son de origen militar, y en tres de los restantes-municipios de Akal, Teya, Ticum- hay gran cantidad, incluso amplia mayoria de firmas, de indígenas representando a su república - caso de los caciques- o a título individual. ${ }^{47}$ Recuerdan estas reuniones las producidas en la época colonial: Pero los fundamentos políticos de la participación son otros, como se verá inmediatamente.

La participación de los militares se expresó en las reuniones convocadas por el gobierno de Yucatán planteando una simple dualidad: "o se respetan a su plenitud los tratados del 14 de diciembre, o tremolemos el estandarte de las cinco estrellas" (Sección auxiliar de Oriente en Loche). ${ }^{68}$ Afirmaban su disposición para empuñar las armas en defensa de lo que visualizaban como derechos de Yucatán, que se resumían en "libertad política". Sólo uno de los batallones que se expiden, la 1a. brigada de artillería de San Benito, Mérida, se declara en contra de los convenios, y satisfecha de lo sucedido:

47 El acta de reunión del pueblo de Ticum (partido de Tekax) comienza diciendo: "[...]reunidos en la casa consistorial los señores alcaldes municipales, el cacique y la república de indigenas, el señor cura de esta parroquia y la mayor parte de este vecindario [...]". Lo mismo sucede en el caso del $\Lambda$ yuntamiento de Teya.

48 Algunos ayuntamientos plantean la misma dualidad que los regimientos y batallones: el dc Campeche, y el do lzamal, por ejemplo. Izamal dice: "subsistencia de los tratados, o nada con México. Rómpase el pacto. $\mathrm{Y}$ con maduro acuerdo, constituyámonos como nos sea más bien visto y conveniente", El siglo Diez y Nueve, 30 de diciembre de 1845;" p. 2.
[...] La primera brigada de artillería local, residente en esta capital, que ardientemente anhelaba el día en que los ultrajes inferidos con la más refinada alevosía, tuviesen a su término [...], se complace de aquel desenlace que más tarde hubiera llegado, puesto que las intenciones eno eran ni sanas ni rectas $[. . .]^{49}$

Esta proclama terminaba decidiendo el desconocimiento del gobierno nacional por parte de Yucatán, y la reasunción de la soberanía del estado. Los militares, ciudadanos armados de Yucatán, se han convertido en un polo de poder al interior del departamento, y es en el momento de la convocatoria en que esto se ve con claridad: firman los coroneles, los tenientes, subtenientes, sargentos y soldados. Han incorporado la lógica deliberativa de los pueblos y ayuntamientos.

\section{Iv. EPflogo}

De hecho, Yucatán volvió a constituirse en nación independiente, el 2 de enero de 1846, unos días después que había caído en México el gobierno de Joaquín Herrera, por el plan de San Luis Potosí. Como consecuencia de la proclama del Batallón de Mérida en San Benito, cayó el gobernador López, y la Asamblea departamental el 2 de enero de 1846 desconoció al supremo gobierno, reasumiendo "de la manera más solemne la plenitud de sus derechos, que ejercerá del modo que con-

49 El siglo diez y nueve, 8 dc encro de 1846; p. 2, col. 3 . 
sidere más conveniente", ${ }^{50}$ para satisfacer la "opinión general" de la península. 51

En México, el gobierno de Paredes Arrillaga se debilitaba cada vez más, y era inminente el estallido de la guerra con Estados Unidos. Se envió al coronel Juan Crisóstomo Cano, a negociar la reincorporación de Yucatán con el argumento de que urgía la defensa de la patria por sobre todas las cosas. Cano dejó entrever que México necesitaría el aporte de trescientos artilleros, y un batallón para la defensa de San Juan de Ulúa de las baterías de Veracruz, sólo por el tiempo de guerra y pagada por el gobierno nacional. Esto recordó viejos tiempos a los yucatecos, y la misión fracasó.

Pero mientras tanto, el 3 de febrero, la Asamblea había convocado a elecciones para un Congreso extraordinario, bajo los mismos criterios del reglamento electoral de marzo de 1841 , y de la Constitución correspondiente. Nuevamente se recurría al mecanismo de abrir el juego político como reivindicación defensiva de la territorialidad. En la convocatoria a elecciones de la Asamblea, se estipularon las condiciones para ser elector, diputado y escrutador. Sabemos que

50 "Memoria de la Secretaría de Estado y del Depacho de Relaciones Interiores y Exteriores de los Estados Unidos Mexicanos, leida al Soberano Congreso Constituyente, por José María Lafragua. México, 1847", docúmento número 29, BN, col. Lafragua, vol. 509, p. 62.

51 upiezas justificativas de la conducta politica de Yucatán, al observar la del gobierno de México, respecto de los convenios de 14 de diciembre de 1843. Mérida de Yucatán, 1846", BN, col. Lafragua, vol. 869. cuando se convocaron estas elecciones, la Asamblea discutió el problema de la representación. ${ }^{52}$ Existió incluso un proyecto de sumar a los diputados elegidos proporcionalmente a la población -"sin distinción de clases"-, otros elegidos sus pares en representación de las clases de agricultores, comerciantes, eclesiásticos y militares, como en el viejo orden colonial..$^{53}$ Proyectos como éste apuntaban en esa coyuntura a cerrar el espacio de la participación política ciudadana, y pueden verse como un esfuerzo por aumentar en las instituciones políticas yucatecas el peso de la representación estamental frente a la ciudadana.

Yucatán se mantuvo, como nación independiente de México, hasta que

52 Una Comisión encargada del cstudio del reglamento electoral afirmaba, en enero de 1846: " $[. .$.$] ha tenido a la vista la ley reglamen-$ taria de 31 de marzo de 1841 , en que halla desenvuelto el principio eminentemente general de la elección directa. Ha introducido, sí, algunas modificaciones que demandan por su naturaleza las actuales circunstancias. El mayor número de representantes del pueblo, su reunión en una sola Cámara, la supresión de algunas de las cualidades y de las restricciones que la Constitución de 1841 y la Ley electoral establece: son puntos cuya utilidad se percibe [...] si se considera que deben expeditarse cuanto sea posible los actos del Congreso y dar cabida en él a todos los yucatecos son sólo que sean ciudadanos en ejercicio de sus derechos y tengan cierto capital o industria productiva. Se trata de construir de nuevo al país: déjense, pues, esas restricciones para los tiempos normales en que elevado ya el edificio social, el principal objeto de los legisladores es engrandecerlo y observarlo [... ]", El siglo Diez y Nueve, 27 de enero de 1846, pp. 1 y 2.

$53 \mathrm{El}$ siglo Diez $y$ Nueve, 27 de febrero de 1846, pp. 1 y 2. 
en agosto de 1846 Santa Anna regresó de Cuba, asumió el gobierno general y restauró la Constitución de 1824 . Yucatán había avalado el plan de Guadalajara y el retorno de Santa Anna. Así, su ministro de Relaciones, el yucateco Manuel Crecencio Rejón, ante la inminencia de la invasión norteamericana restauraría, en octubre de 1846, la vigencia de los tratados de diciembre de 1843, y derogaría el arancel de 1844.

Pero la paz no duraría en la península: el 25 de octubre, Campeche se negaría a reconocer obediencia al gobierno, y declararía en vigencia la Constitución de 1824. Este movimiento fue sofocado, pero cuando se hacía la convocatoria a un nuevo Congreso general, en diciembre 8 de 1846 , estalló la sedición en Campeche, donde se continuaba en una posición secesionista. El movimiento de este puerto estaba alentado por el deseo de evitar la participación de Yucatán en la guerra con los norteamericanos: éstos bloquearían los puertos de Yucatán como lo habían hecho con los de Tabasco, y Yucatán quedaría en la ruina, pues la marina mexicana no podría brindarle auxilio. ${ }^{54}$ El gobernador Miguel Barbachano fue derrocado por los campechanos, y Yucatán se declaró neutral en la guerra con los norteamericanos. Pero en julio de 1847 , se iniciaría nuevamente en Valladolid una insurrección que cerraría definitivamente este ciclo iniciado en 1840 ,

54 AHSRE, "Documentos referentes a la subversión ocurrida en Yucatán, con motivo de su pretensión de independizarse del gobierno mexicano", $1840-46,3-3-4025$, fols. 20 y ss. y que reintegraría definitivamente Yucatán a la república mexicana en agosto de 1848 , luego de un largo peregrinaje por las oficinas de los gobiernos de Estados Unidos, Inglaterra y España. El aprendizaje de la guerra para los indigenas yucatecos significó mucho más que en el simple hecho de empunar las armas, como los historiadores de la época creyeron: tal vez, y muy probablemente, haya sido una experiencia de participación, un acercamiento a las prácticas de la política liberal, y una toma de conciencia repentina, a través de la inclusión forzosa en los mecanismos formales de una política de guerra desde su real exclusión.

En este punto, si se tuviera que responder a la pregunta que se hacía Howard Cline, respecto de cómo considerar al Yucatán de mediados del siglo pasado, como una parte integral de la república mexicana, o como una república independiente como Guatemala, ¿cuál sería la respuesta?

\section{A MODO DE CONCLUSIONES}

En 1843, un articulista de El siglo Diez y Nueve de Yucatán planteaba la "cuestión política de Yucatán" en torno a dos preguntas: ¿Era Yucatán un estado soberano cuando se unió para formar la república mexicana? ¿Mantuvo la soberanía o la perdió en el hecho mismo de realizar aquella unión? La respuesta fue que Yucatán era un estado soberano antes de la conquista española, y que, a la caída del imperio colonial, se retornó a esa 
soberania original. 55 En diciembre de 1845, el Ayuntamiento de Chemax, partido de Valladolid, decía disponiéndose a la guerra por "nuestros naturales derechos", que si se fracasaba en la lucha "Yucatán, Tabasco y las Chiapas están como marcadas por la naturaleza, desde su fundación salvaje; a formar algún día, acaso no muy remoto de nosotros, una república brillante en el siglo de la civilización [...]"56 En el mismo artículo, se hablaba de los sentimientos de nacionalidad, hermandad y fraternidad que aún unían a México. Creo que estos testimonios responden de algún modo a la pregunta inicial: la defensa de la autonomía pudo haber llevado a Yucatán a convertirse en una república independiente.

El caso de Yucatán demuestra cómo la dimensión territorial del poder incidió en el proceso de formación de la república federal. Lo que Yucatán estaba defendiendo, tras el derecho de libre administración interna que otorgaba a los estados la Constitución de 1824, era el derecho de institucionalizar política, constitucional y financieramente su autonomía como estado territorial. La territorialidad había emergido durante la época colonial como consecuencia del débil control administrativo que ejercía el Estado colonial sobre todo el territorio de la Nueva España. El poder político se estructuró entonces en torno a las clases propietarias locales, quienes definieron sus intereses particulares

55 El siglo Diez y Nueve, 25 de febrero de 1843 , pp. 3 y 4.

56 lbid., 25 de diciembre de 1845, pp. 1, 2 y 3. como intereses generales del territorio. Este proceso fue muy acentuado en Yucatán, donde el aislamiento geográfico imponía una muy laxa relación con el Estado desde la época colonial. ${ }^{57}$

En las fuentes que aquí se han analizado se presenta el problema de la integración del "territorio" - cuya soberanía no se discute- a una entidad mayor. Ese problema se plantea en términos de pérdidas y beneficios para la soberanía territorial, a la cual se legitima históricamente. Esto no puede confundirse con la búsqueda de un sistema de organización federalista para la república. Más bien podría afirmarse que lo que está en juego es el propio concepto de soberanía territorial, condensado en el principio de autonomía político-administrativa, que los yucatecos ven "amenazado"

57 "In a former despatche I adduced the evidence of the feeble influence profesed in Yucatan, by the supreme government of Mcxico. It is alleged by the provincials, that the 'union' affords neither protection nor profits to Yucatan. It is true that uniformity in religion prevails, but the ab-original idiom of the people is the lengua maya; while the castilian is principally confined to the higher class. In result, the inclinations and interests of the inhabitants of mexican Yucatan, are anything but mexican." Decía el cónsul británico John Parkinson, en octubre de 1839. F.O., 50, 129. ("En un comunicado anterior yo señalaba la evidencia de la débil influencia del supremo gobierno de México sobre Yucatán. Arguyen los de dicha provincia que la 'Unión' no aporta protección ni beneficios para Yucatán. Es verdad que la uniformidad religiosa prevalece, pero la lengua aborigen de la gente es la maya, mientras que el castellano queda confinado a las clases altas. Como resultado, las inclinaciones e intereses de los yucatecos mexicanos, no son sino los mexicanos.) 


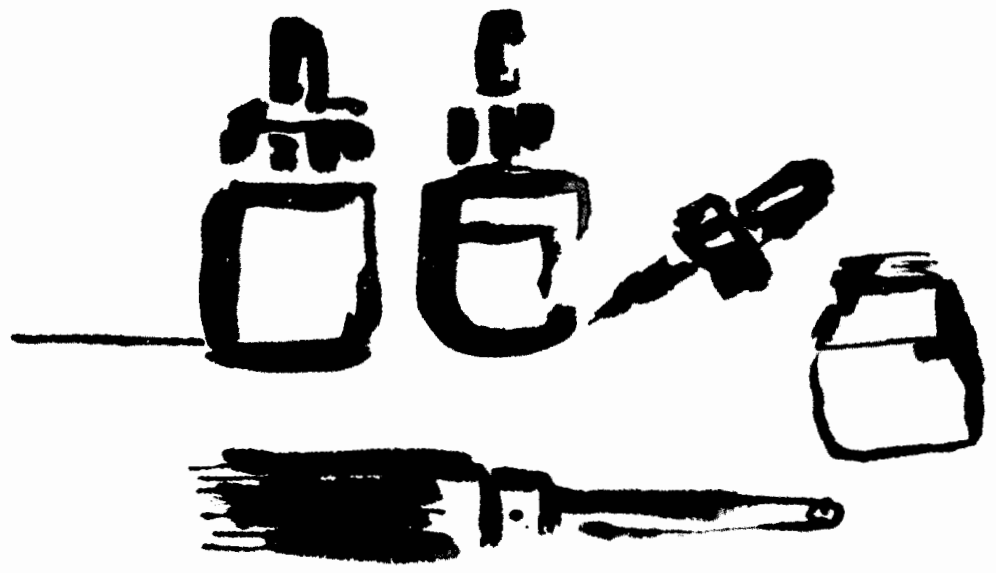

en una unión con México impuesta y fundada sobre la uniformidad administrativa. El surgimiento entre 18421843 de una facción hispanófila en Yucatán en este sentido, además de indicar la estrecha relación que los yucatecos mantenían con los españoles en Cuba, confirma la hipótesis de que, lo que estaba en juego para los yucatecos, era la autonomía administrativa y la libre determinación política. En definitiva: los términos y modo de unión a una entidad política nacional. ${ }^{58}$ Fuese a España o a México, lo

58 Cuando, entre fines de 1842 y 1843 , surge en Yucatán, y especialmente en Campeche y Sisal, una facción que promueve la anexión a España "bajo ciertas condiciones antes que someterse a México" se hace claro el fondo del que importaba era mantener la garantía de libertad de gobierno, de acuerdo con las necesidades $e$ intereses locales.

En este contexto, la defensa de los intereses territoriales fue visualizada

problema. El movimiento hispanófilo no prosperó, porque tanto españoles como yucatecos terminaron advirtiendo la marcada diferencia de los regímenes políticos a que aspiraban unos $y$ otros. Los españoles consideraron que la ancxión de Yucatán a Cuba produciria grandes alteraciones en la isla, por el ejemplo político que daban las instituciones yucatecas. Recordaban además que Yucatán había sido una carga económica para el imperio, al depender del situado de México para su sostenimiento. AHSRE, La Habana, $7 / 2 / 1843$, Jerónimo Valdés, capitán general de la isla de Cuba al secretario de Estado y del Despacho. AHSRE, "Correspondencia del ministro de España", desp. 312, 24 de junio de 
política y militarmente: en el marco de una unión de tipo confederado y a través de diputados, representantes en México de los territorios, no del pueblo de la Unión, y por medio de las milicias ciudadanas en la guerra.

Asimismo, este movimiento de defensa de la soberanía local tuvo por correlato, en el interior del estado, una redefinición de las relaciones de poder, de la autoridad y de la representación política, potenciada por el enfrentamiento armado con México. Sin embargo, los cambios producidos en la vida política del estado se explican tanto por el impacto que causó la forzosa militarización de la sociedad, como por un deslizamiento continuo de la política entre los fundamentos doctrinarios e institucionales de tradición colonial y los principios e instituciones propias de la modernidad. Los cambios aquí analizados confirman la hipótesis de la existencia de una estrecha relación entre guerra y política en la vida política yucateca entre 1840 y 1846 , pero también y fundamentalmente, la complejizan, puesto que se adiverte la presencia de tradiciones doctrinarias y de gobierno que se hallaban en tensión, se intersectaban y superponían.

Pero, sin embargo, esta historia de gobernabilidad territorial $e$ ingober-

1843, doc. 3; pp. 6 y 7. Los yucatecos vieron finalmente que su "soberanía" política e institucional iba a afectarse "sin que hiciese Castilla concesiones muy repugnantes y peligrosas, $o$ Yucatán sacrificios aún mayores a los que México exige": España cra aún "monárquica y aristocrática", y Yucatán "republicano y con instituciones democráticas". El siglo diez y nueve, 15 de noviembre de 1842, p. 4 . nabilidad nacional, en el caso de Yucatán, quedaría abortada: la suble-vación indígena de 1847 eliminaría todas las posibilidades de control gubernativo territorial, y de autonomía política y financiera. La lucha por la soberanía territorial se convertiría entonces en una lucha por la sobrevivencia como entidad política y administrativa.

\section{FUENTES}

\section{A) Inéditas:}

-Archivo General de la Nación (AGN):

Gobernación: Sin Sección, cajas 179, 242, $247,269,282,323,356$.

-Archivo Histórico de la Secretaría de

Relaciones Exteriores:

Asunto Yucatán.

Asunto Consulado en La Habana, Reseñas Políticas (1841-1843).

Asunto Correspondencia del ministro de España en México (1842-1843).

Asunto Informes del Consulado en Nueva Orleans (1840)

-Biblioteca Nacional (BN):

Folletería Colección Lafragua, Fondo Reservado.

-Great Britain Public Record Oflice: Foreign Office, General Correspondence of Mexico. FO. 50, 1839-1841, 1843, 1844, 1845,1846 . Se consultaron sólo en las fechas que resultaban significativas en los acontecimientos políticos entre México y Yucatán. Micropelículas en la Biblioteca Daniel Cossío Villegas del colmex.

B) Editas:

I. Publicactones pertódicas:

-Diario del Gobierno de la República Mexicana, 1840-43. Hemeroteca Nacional. 
- El siglo Diez y Nueve, periódico oficial de Yucatán, 1840-1841, 1842, 1843, $1844,1845,1846$. Hemeroteca Nacional.

\section{Bibliografia:}

-Acereto, Albino, Evolución histórica de las relaciones entre México y Yucatán, México, 1907.

-Ancona, Eligio, Historia de Yucatán desde la época más remota hasta nuestros días, Mérida, 1917.

-Aznar Barbachano, Tomás, "Informe dirigido al Ministerio de Fomento el 15 de octubre de 1856, por su agente en Campeche, don Tomás Barbachapo, sobre tierras baldías y la colonización. del Yucatán" (1856), en Las mejoras materiales, periodico espectalmente consagrado a la industria, agricultura, comercio, colonización, estadística y admintstración pública, Campeche, t. 1, pp. 40-86, en Yucatán, textos para su historia, I, SEP/ Instituto Mora/Gobierno del Estado de Yucatán, México 1988, pp. 200-214.

-Aznar Pérez, Alonso, Colección de leyes, decretos y órdenes o acuerdos del Poder Legislativo del Estado Libre y Soberano de Yucatán, Mérida, 1850, t. II.

-Baqueiro, Serapio, Bosquejo histórico de Yucatán, Mérida, 1913.

-Baranda, Joaquín, Recordaciones históricas, México, s.a., t. I.

"Correspondencia inédita de Manuel Crescencio Rejón", recop. y notas de Carlos Echánove Trujillo, Archivo Histórico Diplomático mexicano, Serie 2, N 5 , México, 1948.

-Pérez Betancourt, Antonio y Ruz Menéndez, Rodolfo, Yucatán: textos de su historia, I y I/, SEP/Instituto Mora/Gobierno del Estado de Yucatán, México, 1988.

-Planes de la Nación Mexicana, Senado de la República/El Colegio de México; 1987 (libro Iv, 1841-1854).

-Regil Estrada, José María, "Comercio en Yucatán", en Estadística de Yucatán.
Boletín de la Soctedad Mextcana de Geografía y Estadística (1852), México, t. III, pp. 324-335, en Yucatan, textos de su historta, I, SEP/Instituto Mora/Gobiemo del Estado de Yucatán, Mêxico, 1988.

-Sierra O'Reilly, Justo, Diario de nuestro viaje a los Estados Unidos (la pretendida anexión de Yucatan), Robledo/Porrúa e hijos, México, 1938.

-Stephens, John L., Viaje a Yucatan, 1841-1842, México, 1938.

-Suárez y Navarro, Juan, Informe sobre las causas y carácter de los frecuentes cambios politicos ocurridos en el Estado de Yucatan y medios que el gobierno debe emplear para la reunión del territorioyucateco..., México, 1861, en Yucatán ante la creación del Estado de Campeche, Ediciones La Muralla, México, 1979.

\section{BIBLIOGRAFIA}

-Betancourt Pérez, Antonio y Sierra Villarreal, José Luis, Yucatán: una historia compartida, SEP/Instituto Mora/Gobierno del Estado de Yucatán, México, 1989.

-Carmagnani, Marcello, "Territorialidad y lederalismo en la formación del Estado Mexicano", en Problemas de la formación del Estado y de la Nación en Hispanoamérica, Inter Nationes, Bonn, 1984, pp. 289-304.

-Civeira Taboada, Miguel, "Yucatán a fìnales del siglo XviI", Memortas de la Primera semana de La Historia de Yucatán, Ediciones de la Universidad de Yucatán, Mérida, 1978, t. I, pp. 265-300.

-Cline, Howard, "El episodio azucarero", en Yucatán. Textos de su historia, SEP/Instituto Mora/Gobierno del Estado de Yucatán, México, 1980, pp. 215-240.

-González Navarro, Moisés, Raza y tierra. La guerra de Castas y el henequén, El Colegio de México, México, 1970. 
-Hamnett, Brian, "Factores regionales en la desintegración del régimen colonial en la Nueva España: el federalismo 1823$1824^{\prime \prime}$, en Problemas de la formación del Estado y de la Nación en Hispanoamértca, Inter Nationes, Bonn, 1984, pp. 304317.

-Joseph, Gilbert, Rediscovering the past at Mexico's periphery. Essays on the history of modern Yucatan, The University of Alabama Press, Alabama, 1986.

-Mediz Bolio, Antonio, La desintegración del Yucatán auténtico, s.e., Mérida, 1954.

-Mena Brito, Bernardino, Historia de las desmembraciones del estado de Yucatán efectuadas por el gobierno nacional: el Petén, Belice, Campeche, Quintana Roo, Ediciones Botas, México, 1962.

-Menéndez, Carlos R., Noventa años de historia de Yucatán (1821-1910), Yucatán, s.e., Mérida, 1937.

-Noriega Elio, Cecilia, El constituyente de 1842, unam, México, 1986.

-Santoni, Pedro, "Los federalistas radicales y la guerra del $47^{\prime \prime}$, tesis de doctorado en Historia, El Colegio de México-Centro de Estudios Históricos, 1987.
-Soto Cedeño, Reynaldo, "Federalismo, centralismo y constitución del Estado", en Estudios, Filosofia, Historia, Letras, ITAM, núm. 2.

, "El Congreso en la Primera República Centralista", tesis de doctorado en Historia, El Colegio de México-Centro de Estudios Históricos, 1989.

-Suárez Molina, Victor M., "Las tendencias regionalistas en la península yucateca. Espíritu y características de las regiones yucatecas en la primera mitad del siglo XIX", en Memorias de la Primera Semana de la Historia de Yucatán, Ediciones de la Universidad de Yucatán, Mérida, 1978, t. II, pp. 9-25.

-Vázquez, Josefìna Zoraida, "El ejército: un dilema del gobierno mexicano (18411864)", en Problemas de la formación del Estado y de la nación en Hispanoamérica, Inter Nationes, Bonn, 1984, pp. 319-338.

-Zanoli Fabila, Betty Luisa de María Auxiliadora, "Liberalismo y monopolio: origenes del federalismo en las ticrras del Mayab", tesis de licenciatura en Ilistoria, unam-Facultad de Filosolía y Letras, México, s.a., 2 vols. 


$$
\sqrt{10}
$$

